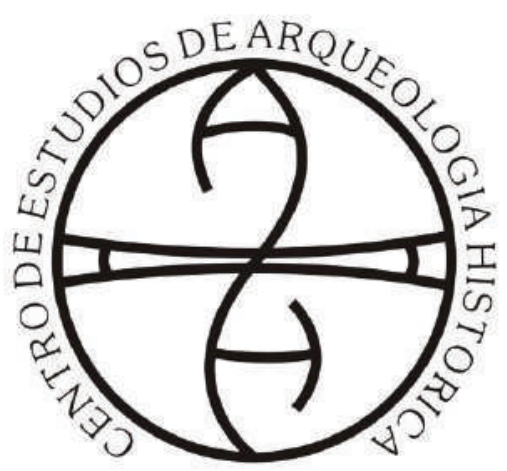

Centro de Estudios de Arqueología Histórica

Universidad Nacional de Rosario

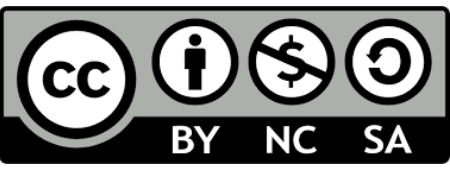

Teoría y Práctica de la Arqueología Histórica

Latinoamericana | Año IX, Volumen 11 | 2020

Revista del Centro de Estudios de Arqueología Histórica, Facultad de Humanidades y Artes,

Universidad Nacional de Rosario

https://teoriaypracticaah.unr.edu.ar/index.php/index

https://rephip.unr.edu.ar/handle/2133/14804

ISSN en línea: 2591-2801

ISSN versión impresa: 2250-866X

Atribución-NoComercial-CompartirIgual 4.0 Internacional (CC BY-NC-SA 4.0)

https://creativecommons.org/licenses/by-nc-sa/4.0/deed.es

Ana María Rocchietti (ID.: http://orcid.org/0000-0003-

0516-9297). San Bartolomé de los Chaná: el final

\title{
SAN BARTolomé de los Chaná: el Final
}

\section{SAN Bartolomé de los Chaná: THE END}

Ana María Rocchietti*

\section{Resumen}

Este artículo está dedicado a hacer una reseña sobre el final del sitio La Boca (Departamento de San Jerónimo, Provincia de Santa Fe, Argentina). La destrucción lateral de la terraza en donde estuvo emplazada la reducción franciscana de San Bartolomé de los Chaná por una bajante extraordinaria del río Coronda, uno de los brazos del río Paraná en su Delta inferior, afectó el depósito arqueológico que contenía una potente distribución cerámica indígena y europea así como distintos elementos que documentaban su existencia. El final de un sitio arqueológico es siempre una posibilidad materialmente sustantiva pero cuando efectivamente ocurre es necesario un análisis reflexivo centralizado en sus implicaciones tanto teóricas como prácticas.

Palabras clave: Reducción franciscana, Delta del Paraná, Indígenas Chaná

\section{Abstract}

This article is dedicated to reviewing the end of La Boca site (Department of San Jerónimo, Province of Santa Fe, Argentina). The lateral destruction of the terrace where the Franciscan reduction of San Bartolomé de los Chaná was located by an extraordinary drop from the Coronda river, one of the arms of the Paraná river in its lower Delta, affected the archaeological deposit that contained a powerful indigenous

* Centro de Estudios en Arqueología Histórica. Facultad de Humanidades y Artes. Universidad Nacional de Rosario. E-Mail: annau2002@yahoo.com.ar 
ceramic distribution and European as well as various elements that documented its existence. The end of an archaeological site is always a materially substantial possibility, but when it does occur, a centralized reflective analysis of its theoretical and practical implications is necessary.

Key words: Franciscan reduction, Paraná Delta, Chaná indigenous people

\section{Introducción}

En Arqueología, los estudios de sitio demarcan un terreno, un espacio en tres dimensiones: superficie del área con vestigios y su profundidad estratigráfica (si la tiene) tomando en cuenta las continuidades y discontinuidades en la distribución de sus contenidos, procurando establecer retrodictivamente su evolución ecosistémica y tafonómica. En los dominios de la arqueología histórica, los registros tienen la finalidad de reconstruir, sistematizar y explicar la sociedad que produjo el emplazamiento de lo que alguna vez fue actividad humana.

En términos generales, los sitios parecen ser una fuente inagotable de información y sobre ellos se realizarán sucesivos trabajos de registro. La lógica dirá que no es así, tanto en el caso en que la extracción de cultura material se agote cuanto en el que la destrucción ecosistémica y el vandalismo conduzcan a su desaparición.

San Bartolomé de los Chaná fue una reducción, puesta en encomienda producto de la política colonial de Hernando Arias de Saavedra (Hernandarias). Oficialmente se la declaró erigida en 1615 y trunca por despoblamiento en 1621 debido a una epidemia de viruela. Estuvo destinada a concentrar familias Chaná y Guaraníes para ser evangelizadas y transformadas en trabajadores rurales. Se emplazó en el paraje de la cañada en donde el río Coronda recibe al arroyo Monje; lugar que lleva el nombre popular de La Boca. Su ubicación cardinal es $32^{\circ} 19^{\prime} 57.42^{\prime \prime}$ S y $60^{\circ} 52^{\prime} 22.26^{\prime \prime}$ W (Figura 1).

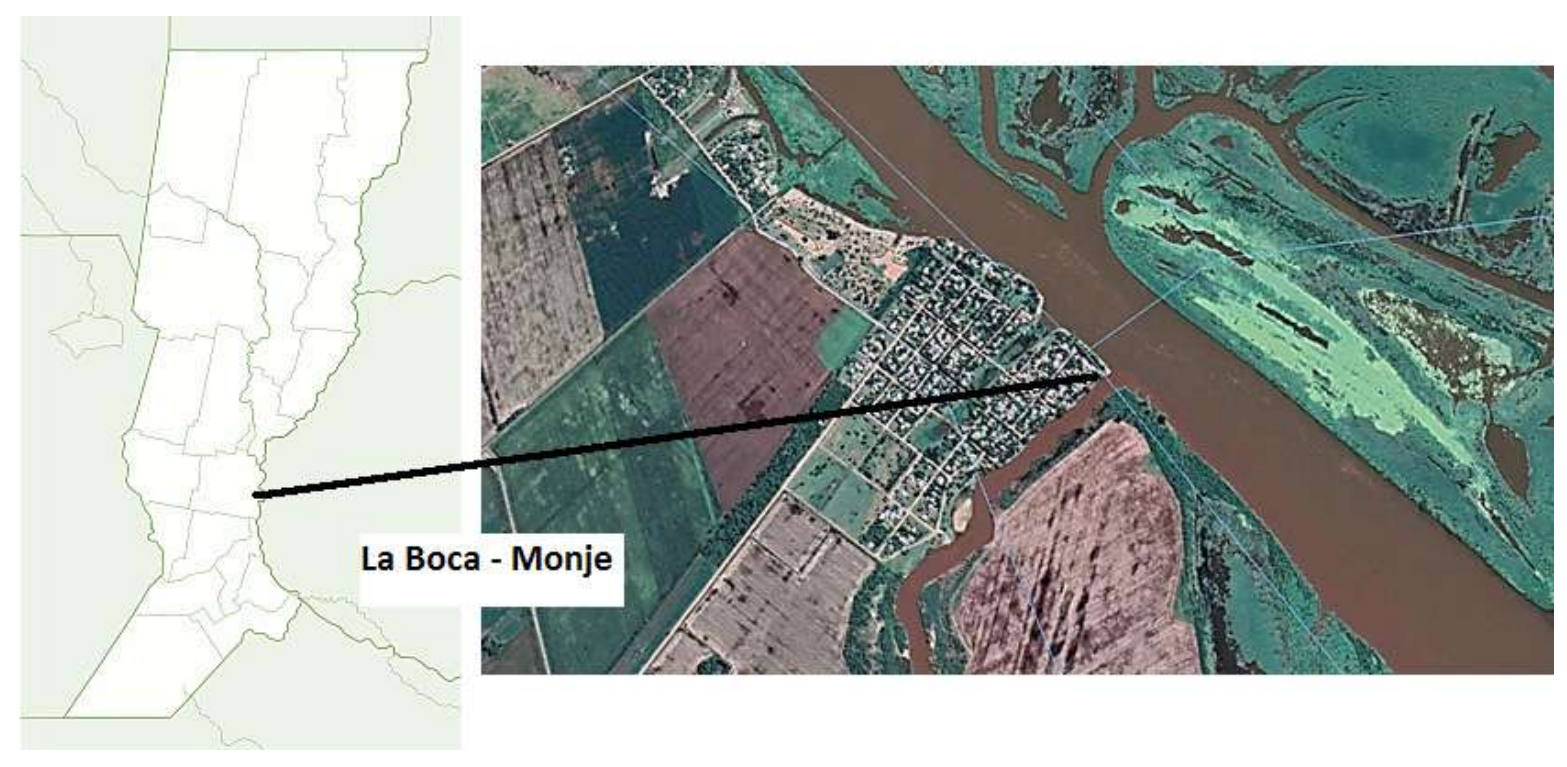

Figura 1. La Boca (San Bartolomé de los Chaná). 
Este trabajo presenta el final de este sitio, valioso porque expresa el poblamiento indígena en encomienda colonial y formula implicancias epistémicas sobre la condición contingente de todo registro que haya concentrado esfuerzos de investigación.

\section{El comienzo del final}

El sitio La Boca, expresión arqueológica de la que fuera la reducción franciscana de San Bartolomé de los Chaná, fue localizado en el año 1990 por nuestro equipo de investigación del Departamento de Arqueología, Escuela de Antropología, Facultad de Humanidades y Artes, Universidad Nacional de Rosario, por casualidad después de una infructuosa prospección en la localidad cercana de Puerto Gaboto. Estaba emplazado como una distribución cerámica alterada en sus primeros centímetros estratigráficos fértiles, en la terraza costera del río Coronda en el punto en que desemboca el arroyo Monje (en la cartografía también Monge, topónimo originado en el apellido de un morador antiguo en ese paraje), frente al delta inferior del Paraná y en la margen derecha. Tanto en aquel tiempo como en la actualidad allí se localiza un balneario dedicado sobre todo al turismo de fin de semana y que convoca a aficionados a la navegación y la pesca. Los habitantes permanentes se dedicaban a esta actividad pero con fines de subsistencia en el contexto de un comercio de suministros para camping de baja escala (carpas, aparejos, faroles, alojamiento, etc.), como pescadores comerciales y como guías en la pesca deportiva. Sobre el sitio se construyeron, hace más de setenta años, viviendas de distinto porte, generalmente ocupadas transitoriamente y en algunas se venden artículos de almacén. El área libre está ocupada por asadores o fogones para cocinar la carne fresca traída por los visitantes o comprada en el lugar para disfrutar de almuerzos y cenas familiares o para acabar con el producto de la pesca después de un día de regata y cosecha de peces en el río (Figura 2).
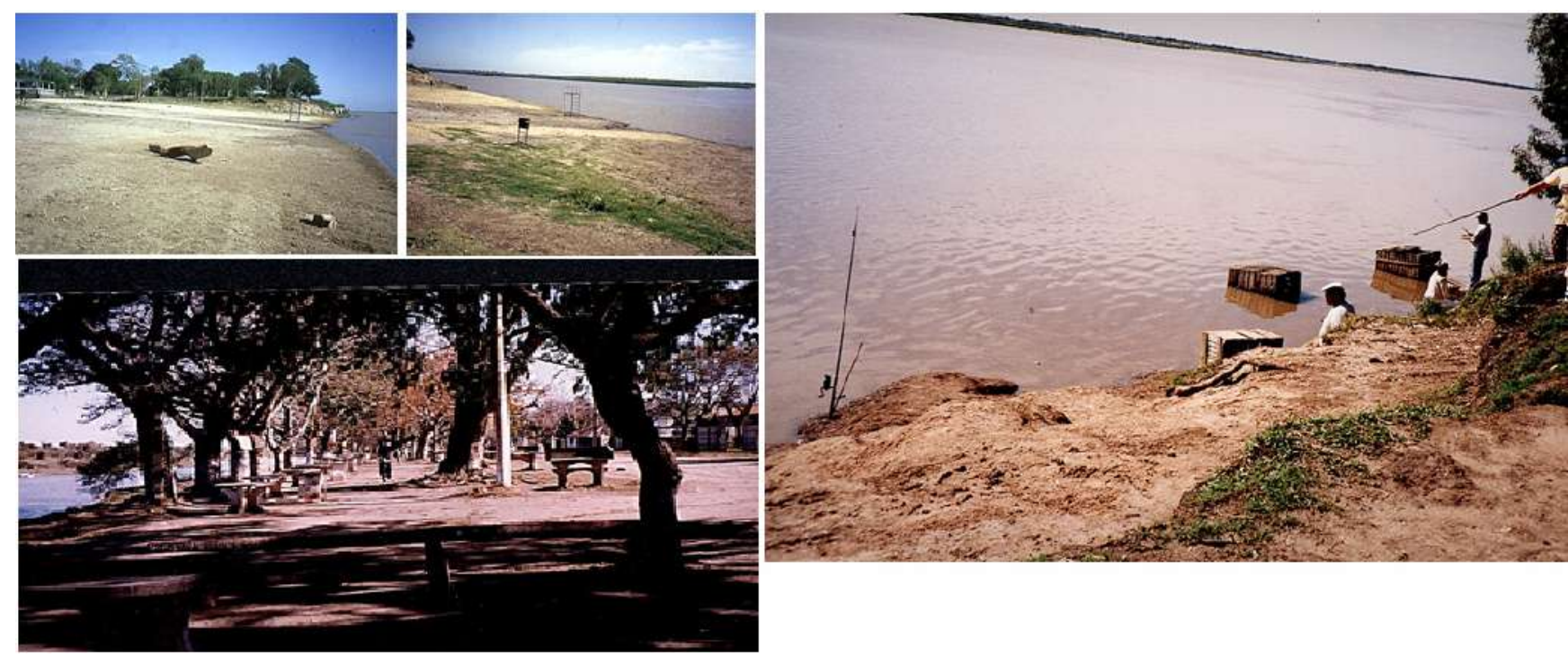

Figura 2. Sitio La Boca. 
La investigación de este yacimiento, enterrado y parcialmente aflorante en algunos sectores, sobre todo por el tránsito a pie de la gente que alquila los espacios para acampar, sirvió de inicio a una investigación destinada a la arqueología de los vestigios dejados por las poblaciones indígenas en esa área en épocas pre-coloniales y coloniales. Las características que señalamos son las mismas que encontramos la primera vez que estuvimos allí. La Dra. Nidia Areces -Departamento de Historia- indicó -cuando todavía los hallazgos ofrecían solamente las cerámicas indígenas características del delta- que ese lugar podía corresponder a la reducción de San Bartolomé, hipótesis confirmada por el tenor de los hallazgos posteriores que aseveran su datación colonial (Comunicación personal). El hallazgo se tornó muy importante porque San Bartolomé de los Chaná, reducción de indios, dependía de un encomendero de Santa Fe, La Vieja, -don Pero (Pedro) Gómez ubicada a 183 kilómetros hacia el norte, fundada por Juan de Garay en 1573.

Prospecciones intensas y sostenidas durante muchos años brindaron 30 sitios indígenas (indios isleros, en homenaje al gentilicio que usan los vecinos que se ven a sí mismos como isleros) pero ninguno relacionado con San Bartolomé. Recorrimos el río Coronda, la isla Chaná, los riachos del Pueblo, el Lules, el Carpincho, el bañado Campo Grande y el arroyo El Laurel (o Los Laureles, según los pescadores) procurando localizar el presunto retiro de los indios en ocasión de la viruela o vestigios de la actividad de la encomienda como, por ejemplo, de vaquería (Figura 3). Pero no los había.

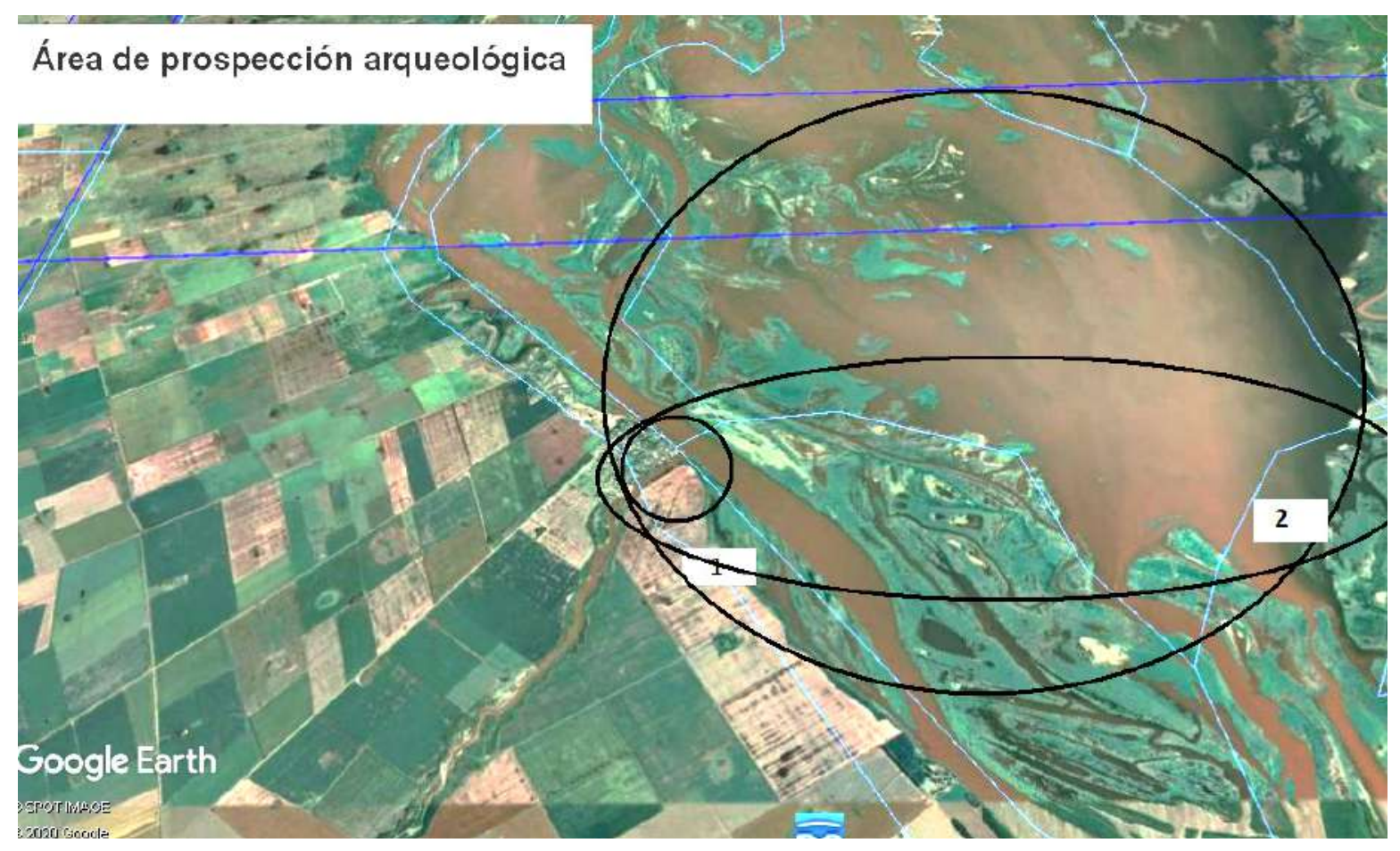

Figura 3. Área de prospección. 1. Inmediaciones de La Boca, 2. Sección extensa. Fuente Google Earth Pro (abril 2020).

Por lo tanto, La Boca (apelativo que sintetizó el yacimiento y el nombre del paraje) permaneció como el único registro de arqueología histórica colonial en esa sección de la cuenca. La excavación 
posicional se llevó a cabo con la participación de docentes y estudiantes de la Cátedra de Metodología, Orientación Arqueología como parte de su entrenamiento en la disciplina y en las técnicas de campo; la profesora Nélida De Grandis se dedicó a estudiar los materiales extraídos en laboratorio y la profesora Mónica Valentini practicó arqueología subacuática en la costa de los dos cursos fluviales (el Coronda y el Monje) y en la costa de Los Laureles, (Rocchietti, et al 1994, 1997, 2005, 2007; Rocchietti et al 1997, 2007; De Grandis 2006),

La Boca fue un sitio arqueológico emblemático para el equipo no solamente por su interés científico sino también por la oportunidad de afianzar la camaradería y por llevar adelante un trabajo que fue sacrificado en muchos sentidos: las dificultades para trasladar estudiantes y equipamiento desde la ciudad de Rosario - a 74 kilómetros de lejanía- en buses de línea, por la falta de fondos, por las dificultades económicas para hacer análisis edafológicos, físicos y químicos y, antes que nada, por llevar a cabo tareas de registro con obstáculos para entrar a los jardines de las residencias con la finalidad de poder definir el alcance y escala de la distribución de materiales así como disponer de un área de excavación parcialmente alterada. El Dr. Daniel Schávelzon asesoró la identificación de las lozas coloniales tempranas y el Agrimensor Benito Vicioso de la Facultad de Ciencias Exactas, Ingeniería y Agrimensura elaboró el modelo topográfico del sitio (Figura 4). La Dra. Amancay Martínez hizo el análisis físico de las cerámicas (Rocchietti et al 1996; 2005, 2007, Rocchietti y De Grandis 1997, 1999; De Grandis 1998, 1999, Valentini 2003, 2006; Valentini y García Cano 2001, 2003).

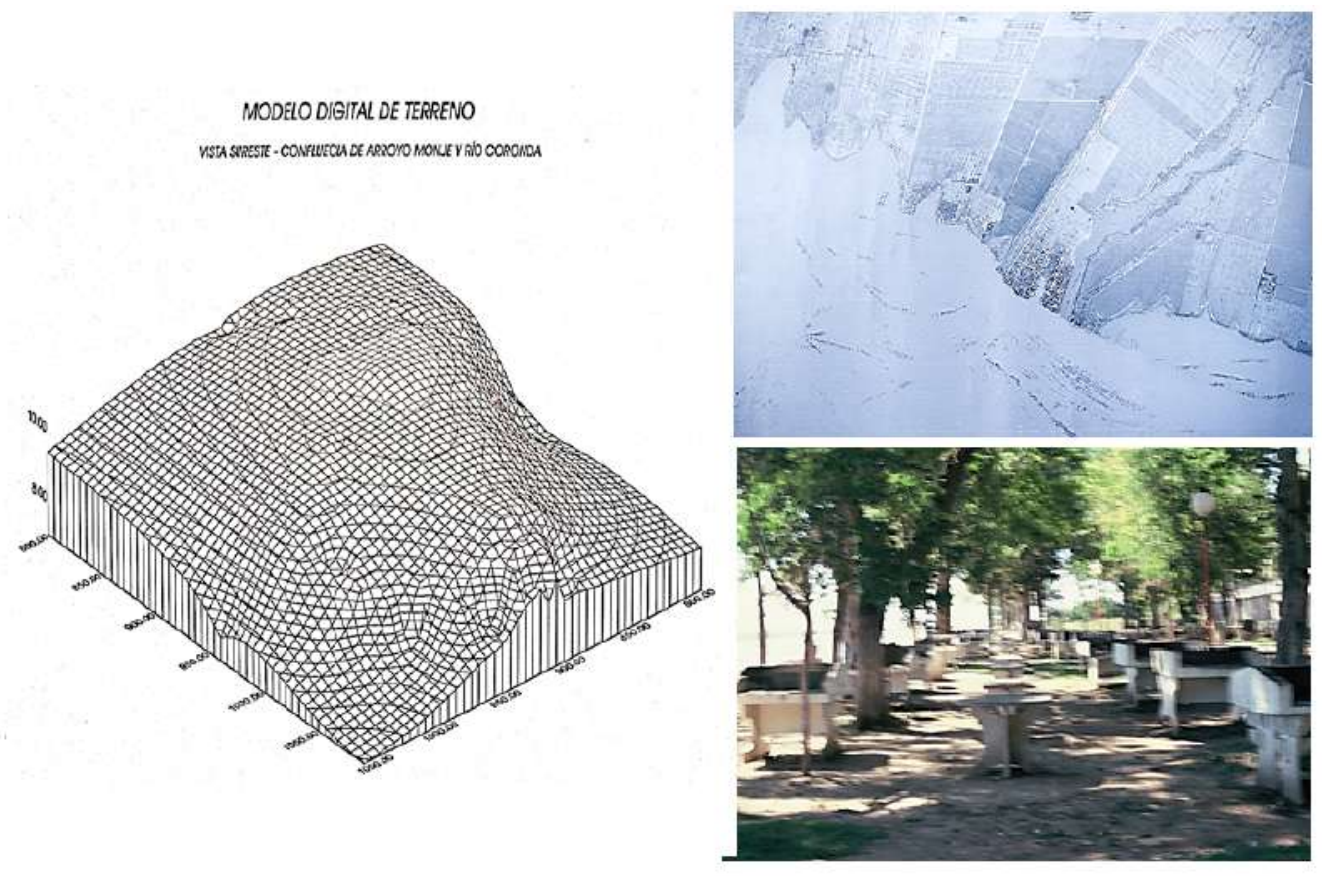

Figura 4. Modelo topográfico de La Boca (Ing. Benito Vicioso).

Generalmente, está casi naturalizada la condición perenne de los yacimientos y de su fuente de información; el proceso de investigación es lento e incierta la posibilidad de retornar a ellos pero es sus- 
tantiva la convicción de que -salvo sucesos fortuitos, como el que narramos- no asistiremos a su final (Figuras 5 y 6).

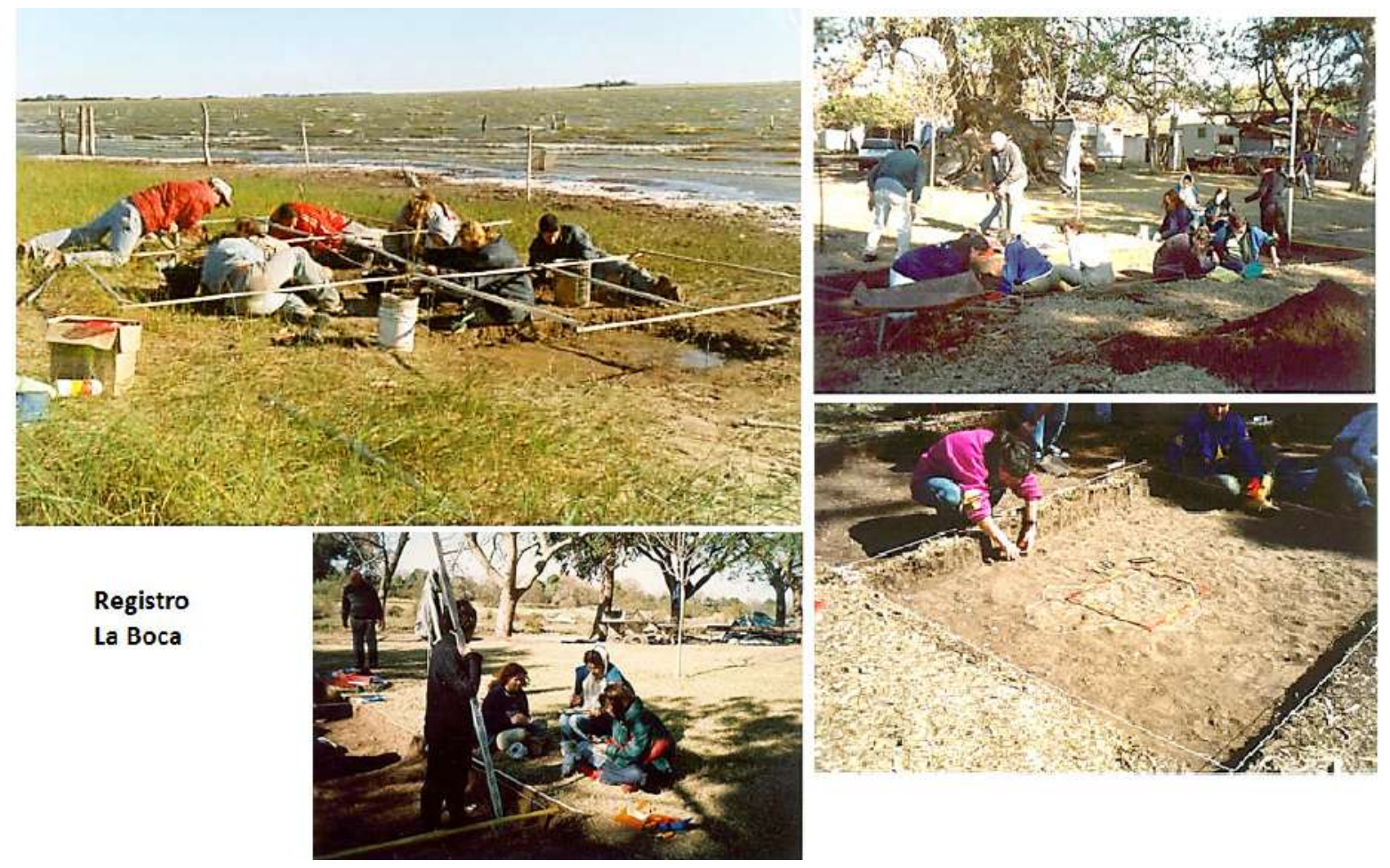

Figura 5. Excavaciones en La Boca del Arroyo Monje.

\section{El suceso inesperado: El Litoral, 7 de septiembre, año 2019}

Este tradicional diario santafesino ${ }^{1}$ anunció que por la bajante extraordinaria del río se había desmoronado la barranca del camping de Monje, que la comuna había cercado el lugar y que pedía que la gente no se acercara y que tomara precauciones. Se cayeron asadores, mesas, un baño público y árboles.

Ingenieros del Ministerio de Infraestructura de Santa Fe llevan a cabo estudios en la zona. Afirman que lo cedido es "irrecuperable" y prevén que pueda volver a ocurrir.

En diálogo con IRE, el presidente comunal de Monje, Pedro Severini, sintetizó: "Nos reunimos con ingenieros de la parte hidráulica del Ministerio de Infraestructura que estudiaron el terreno donde se socavó todo". Y amplió: “Tenemos que hacer un recopilamiento con los datos de las últimas veces que se desmoronó y llevarlos a Santa Fe, donde están haciendo un relevamiento de la situación, pero creo que soluciones no hay".

En relación al terreno cedido Severini remarcó: "El agua es parte del mismo sostén que hace que la barranca no ceda, cada vez que baja el río de una forma importante eso se puede desmoronar, prácticamente se hizo un túnel debajo y hay que saber si se va a seguir degradando".

Luego, aseguró que existe otra porción de tierra que también está a punto de caer: "Se socavó todo con la cantidad de agua que viene de cuencas arribas y nos quieren mandar más todavía, así que más complicados vamos a estar". (El Litoral, 7 de septiembre, año 2019). 

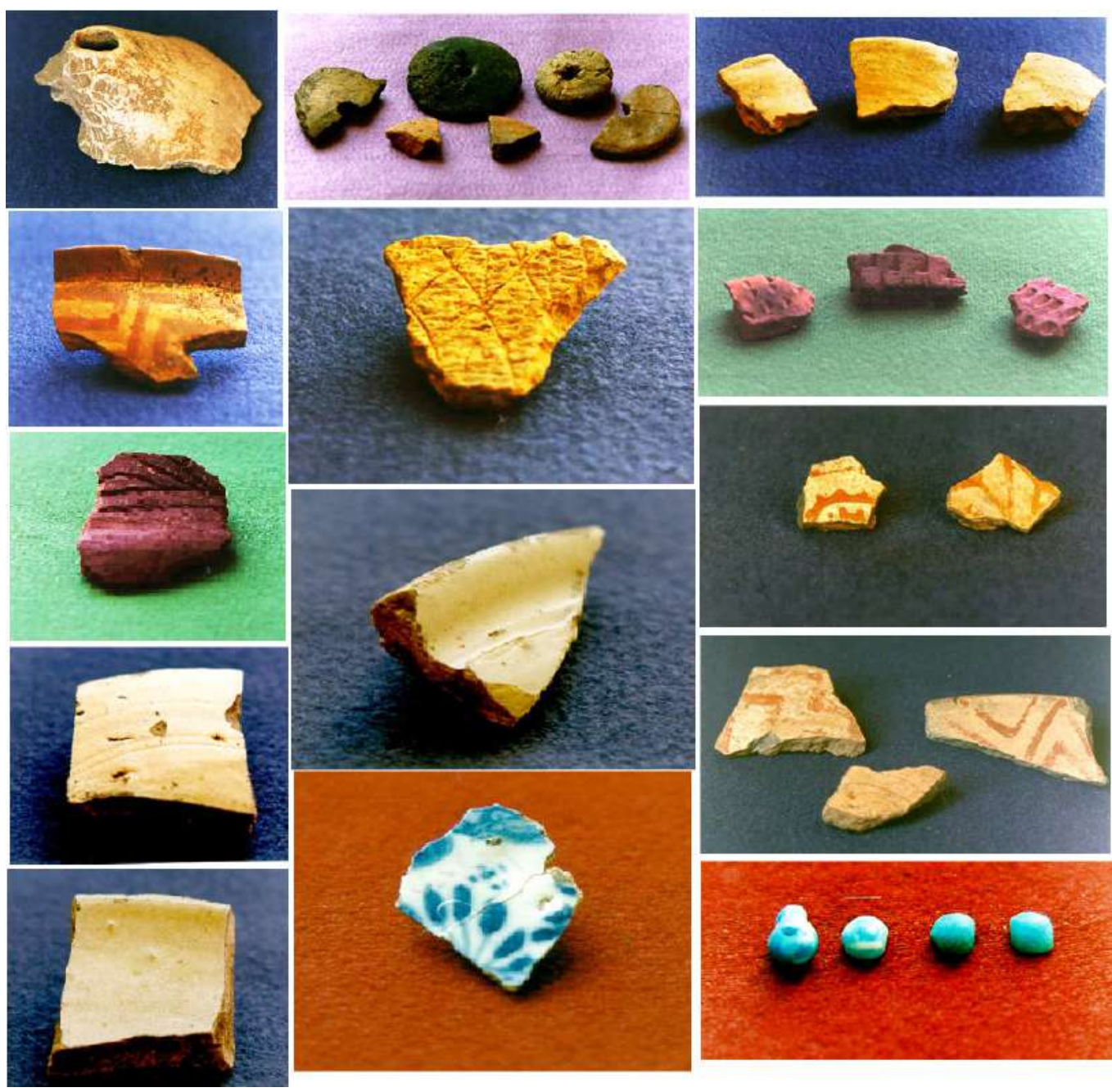

Figura 6. La Boca: Materiales arqueológicos

Las márgenes del Paraná y de sus afluentes son generalmente bajíos inundables o barrancas limo-arenosas erosionadas impiadosamente por la deriva del agua en ciclos alternantes de crecientes y bajantes del agua. En la Boca y en el resto de los parajes crece un bosque achaparrado y pastizales de paja brava. Se trata de un ecosistema de humedal, de carácter aluvional y colector de una gran cuenca cuya capacidad de agua y sedimento es enorme y ha formado un delta geológicamente reciente. El un paisaje de agua donde los asentamientos humanos se han adaptado a un potencial de riqueza en especies y de desastres hidrológicos inesperados. La actividad forestal ha desplazado el bosque nativo de albardón y la ganadería vacuna de engorde, introducida en las islas, ha contribuido a modificar los de pajonales primigenios. La zona conjuga características de la llanura pampeana y de la mesopotamia argentina.

En los albardones es posible hallar ranchadas en pie y restos desmoronados de ellas cuando ya no alojan pobladores; las viviendas más elaboradas (con mampuestos de ladrillo o de concreto) están en la costa firme, cada vez más densamente poblada. 
La Boca dista 10 kilómetros respecto al pueblo de Monje, una localidad urbana de entorno rural ubicada junto a la ruta 11 que une las ciudades de Santa Fe y Rosario. El camino al yacimiento fue durante muchos años de tierra y ahora es un mejorado; cuando llueve se vuelve intransitable y el balneario queda aislado. Viajábamos en un camión de la Municipalidad entre campos dedicados a la cría de ganado y a la agricultura.

Los indígenas debieron vivir en ese ambiente de la caza, de la pesca y de las chacras. Su identidad fue asignada por los españoles como Chaná y así lo consigna el nombre de la reducción. Las noticias sobre su género de vida y sobre sus orígenes son vagos, fragmentarios y escasos. Probablemente debieron luchar, ellos también, contra la inundación, imagen fundamental de ese paisaje. No obstante, la región es templada y de agradable contexto climático, atractiva para vacacionar y de acceso relativamente sencillo. Así como las crecientes dejan áreas fuertemente inundadas en sectores de sedimentos arcillosos y superficies impermeables por varios meses (localmente se llaman bañados) y el centro de las islas (maciega) pueden permanecer anegadas casi todo el año, hay bajantes extraordinarias sea porque en la alta cuenca actúa el régimen de represas, sea porque se evacua con rapidez el agua, sea porque hay sequía prolongada. El clima no parece haber cambiado en relación con el que existía en tiempo de los chaná aunque ahora se sabe más sobre la influencia de los fenómenos $\mathrm{ENSO}^{2}$ en el cono sur y se tiene una mejor explicación de sus alternancias. Geomorfológicamente, las islas tienen distintos tamaños (las hay extensas y las hay reducidas), hay bancales y los riachos describen meandros irregulares que suelen cambiar de rumbo o abrir brechas entre los sedimentos haciendo impreciso el levantamiento de los contornos de los parajes (muchos con sitios arqueológicos). Los topónimos río, riacho, madrejón, cañada, cañadita, boca, boquita están por todas partes: por el nombre que se usa en el litoral de los ríos santafesinos y entrerrianos al fenómeno de desembocadura y grandes y pequeños cuerpos de agua que resultan de la deriva en relación con los declives del terreno y su potencia para abrirse camino hacia los cursos principales.

San Bartolomé se hallaba emplazada en el Complejo Deltaico del río Paraná -sección superior de islas- en un ambiente ripario, esto es, un ámbito de río en el que la característica funcional dominante que conecta y contiene elementos propios y adyacentes es una llanura de inundación y áreas de su contacto con tierra firme donde predomina el concepto de corredor sobre el de ecotono configurando un sistema de humedal en el que existe una secuencia de ecosistemas, con flujos de energía y especies que configuran una heterogeneidad de tamaños y elementos. El Paraná tiene un régimen pulsátil anual con bajantes entre agosto y septiembre y crecientes entre el fin del verano y comienzos del otoño.

El paisaje contiene Formaciones arbóreas (bosques de las partes altas), Formaciones herbáceas y arbustales en las intermedias y acuáticas (flotantes) en las bajas. En ese ámbito se pueden señalar varios hábitats: llanura aluvial del Paraná, llanura dendrítica, red de drenaje anastomosado y terrazas. Los depósitos se forman en el interior del cauce y fuera de él en la llanura de bancos, en el área de derrames y en la llanura de meandros. El Coronda produce grandes cuerpos de agua sobre la banda occidental con los ecosistemas que se suelen formar en las áreas con bañados y multitud de riachos de escurrimiento lento (Azeñolaza et al, 2009).

El relieve plano de las islas se interrumpe en los albardones: acumulaciones en forma de huso, formados por la acumulación sedimentaria fluvial lateral, los cuales culminan en un suelo húmico muy fértil y ácido. Hay arenas marinas producto de ingresiones holocénicas (Iriondo y Scotta 1978, Iriondo 1993, Malvarez 1993) y depósitos limo-arcillosos de gran potencia (Bonfils 1962). El Paraná tiene aguas de origen subtropical y su volumen crece entre septiembre y marzo.

Los parajes en donde hemos localizado sitios arqueológicos poseen un perfil típico: albardón formado por agradación que declina hacia el centro de la isla demarcando una cubeta interior ocupada por 
agua y vegetación graminosa, pajonales, juncales y varillas. Los árboles más altos se encuentran en el albardón y asumen fisonomía de bosque (Figura 7).

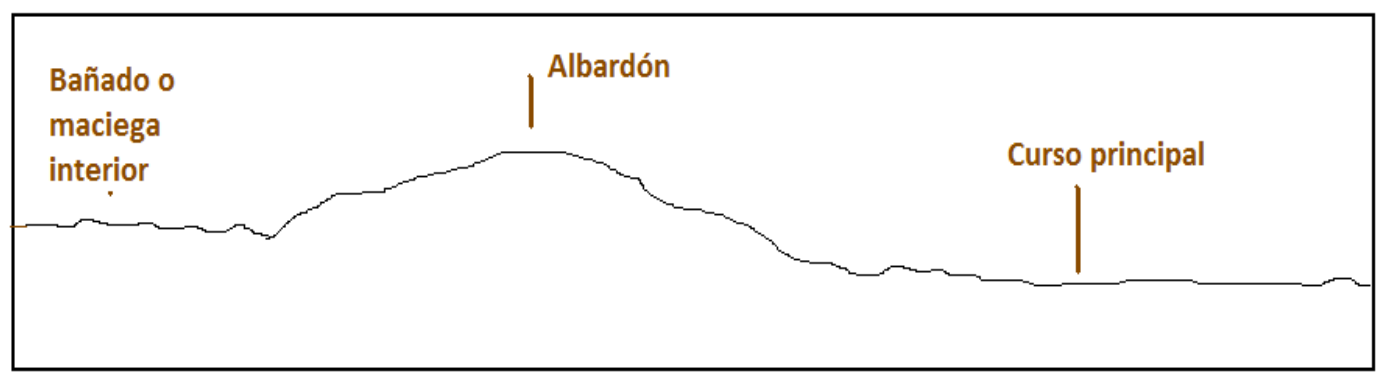

Figura 7. Perfil generalizado de isla.

En la tierra firme (la barranca costera de la llanura pampeana) el perfil plano está ocupado por el pastizal. En la Boca existían (y aún queda algún ejemplar) ombúes entremezclados con ejemplares de árboles implantados para dar sombra. Los ejemplares dominantes (que aquí quiere decir "los que no fueron talados") son timbós negros destinados a proteger con su sombra el descanso y el disfrute de los acampantes.

Las especies de peces y de animales terrestres hacen de esta tierra un ambiente pródigo para alimentar población humana. Curiosamente, las estratigrafías que realizamos en tierra firme y en islas dieron pocos vestigios de esa naturaleza.

En síntesis: el suceso inesperado que destruyó parte del sitio de San Bartolomé y del balneario La Boca no fue sino un episodio coherente con el patrón funcional de este paisaje.

\section{Estructura del sitio}

La Boca es un polígono estrecho comprendido entre el arroyo Monje y un área plana de un antiguo paleo-cauce subordinado a aquél. La barranca tiene 2 metros de altura sobre el río cuando hay bajante. El terreno describe un falso albardón demarcado por él y recibe el nombre local de la cañadita. Hace unos años fue rellenada con arena para tener una playa que complementara la oferta del balneario. La planta original de La Boca está en este lugar: son casitas antiguas, muchas de ellas pertenecientes a pescadores acopiadores y a familias que se consideran "residentes naturales", ocupantes informales que con el tiempo progresaron.

Los restos de la reducción no tienen constructivos; son básicamente conjuntos cerámicos muy fragmentados. Los indígenas reducidos allí eran Chaná y Guarani, de acuerdo con la costumbre española de llevar a estos últimos consigo porque los consideraban sus aliados e introductores en el país del río y, quizá, por la convicción de que la agricultura es la base de la riqueza de las naciones.

Chaná, Guaraní y españoles están representados en su identidad histórica por tiestos y poco más. Fue el estudio de laboratorio el que permitió inferir las características de la reducción y del modo de vida español (en su versión franciscana) Visto desde el Coronda -en ocasión de bajante cuando el agua deja una angosta playa- el sitio tiene una estratigrafía consistente en un generoso suelo negro (potencia de $0.60 \mathrm{~m}$ ); una columna loéssica pampeana típica que apoya sobre un concreto de carbonato consolidado que el agua carcome en dependencia de su dureza. Es una ambiente sin piedras; todo es sedimento fino 
y friable. Los materiales arqueológicos se encuentran dentro del suelo, desplazados únicamente cerca de las raíces de los árboles y de los asadores (Figura 8).
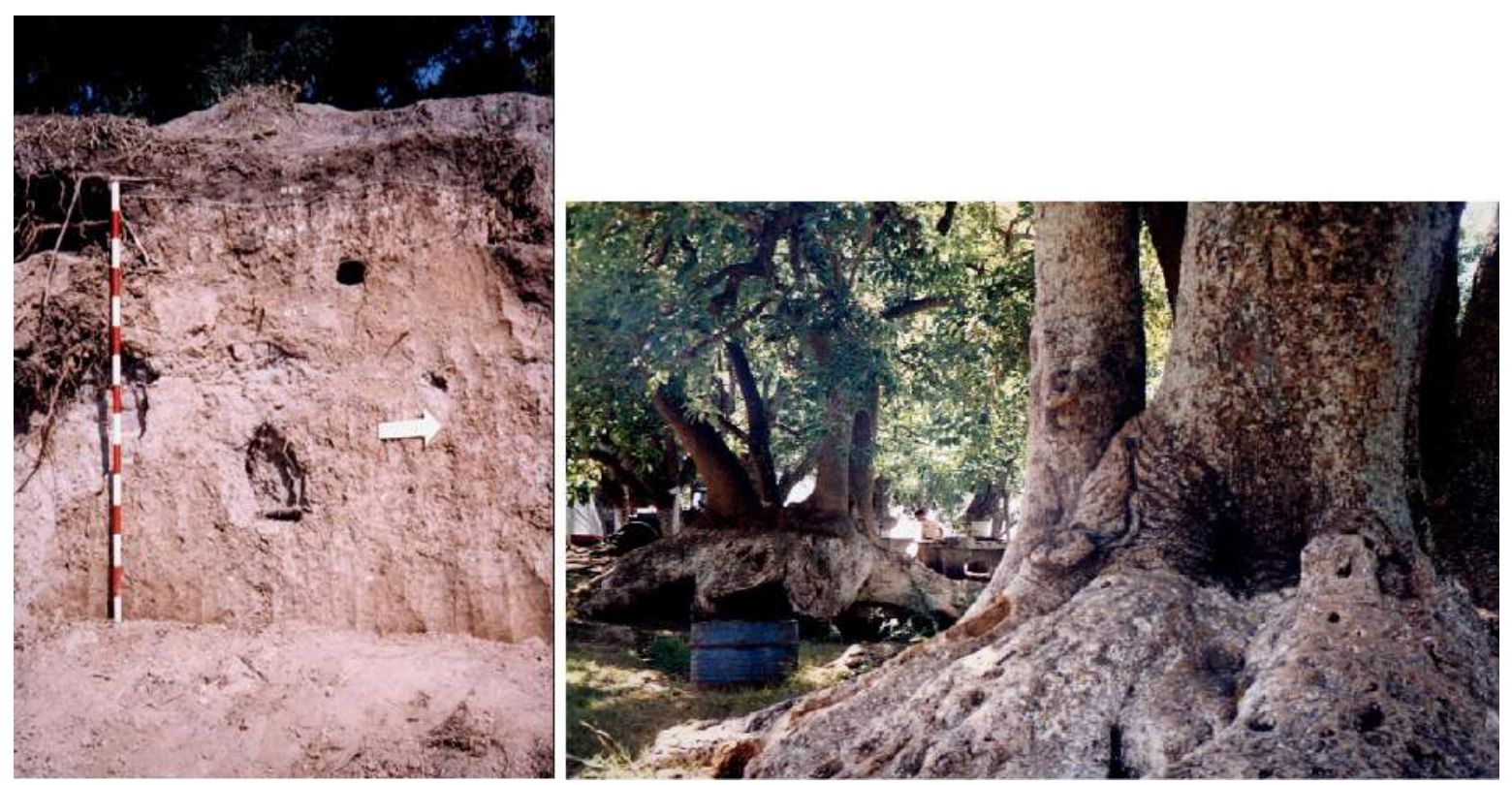

Figura 8. Perfil de la barranca.

Deben estar también en el interior de las viviendas pero la densidad de construcciones es muy alto y no es posible acceder a ellas. La distribución horizontal de los tiestos es relativamente restringida: está confinada a la parte más alta del terreno y desciende notablemente hacia el oeste, no sobrepasa una torre que suministra agua al balneario y no existe en la cañadita. Hacia el norte, hay -a la vera del Coronda en terraza costera- otros sitios pero en completa discontinuidad con La Boca. Tienen afinidad con las cerámicas de ésta (es decir, Chaná) pero sin materiales españoles.

Nuestra identificación de las cerámicas asumió que las que corresponderían a este grupo indígena se inscriben en la formación Goya-Malabrigo pero con una expresión o fisonomía atenuada si se la compara con yacimientos ubicados mucho más al norte en el Paraná (Cornero 2018, 2019). Las cerámicas guaraní son las típicas (pintadas y corrugadas) y tienen una presencia importante. Sobre lo que no quedan dudas es sobre el constituyente español del sitio por su contenido en mayólicas y cuentas de vidrio venecianas.

Los habitantes de la Boca nos refirieron la existencia de consolidados cuando construyeron sus casas, lo que podría atribuirse a la mención de una iglesia de tapia en la documentación. Pero no la hallamos. Por lo tanto, la excavación se enfocó en la sección menos alterada del terreno a la que por tal la denominamos área crítica y se procedió a un decapage total después de los primeros 0.15 metros de profundidad. Consideramos que -salvo por procesos tafonómicos- el registro es confiable y que representa la modalidad habitual de depósito en la región pero al margen de los procesos de inundación.

Los materiales se incluían en el suelo en forma de una nube dispersa, sin área de combustión, con un grado relativamente bajo de rodamiento (por haber estado alguna vez en superficie en algunos casos) y, entre 0.15 y $0.45 \mathrm{~m}$ de profundidad combinadas las tres tradiciones socio-históricas (Chaná, Guaraní y europea). Las tres mantuvieron, tanto en técnica como en decoración, sus identidades separadas porque 
no constatamos que se combinaran ni que hubiera tiestos que documentaran la presencia de alfarerías mestizas (Rocchietti y De Grandis 2018). La acción franciscana es apenas visible porque no hallamos cruces ni otros elementos que denotaran un pequeño conglomerado cristiano. No estimamos a las cuentas de vidrio como partes de rosarios sino -como era habitual en la colonización su entrega para conseguir la voluntad de los indígenas para trabajar y para volverse feligreses de una religión exótica. Más abajo, los materiales comenzaron a escasear pero pertenecían a la tradición Goya - Malabrigo. Por lo tanto, supusimos que pudo existir ahí una población de las islas o Chanás que incursionaron en La Boca previamente a la reducción porque esos materiales son coherentes con los que provienen de ellas. Sabemos, por la documentación, que los indios escaparon al delta por una epidemia de viruela. Era, entonces, su hábitat ancestral (Rocchietti 2002; Rocchietti y De Grandis 2011, 2013, 2014, 2015 a, 2016, 2019). En síntesis: hay motivos suficientes para establecer que en este lugar estuvo San Bartolomé de los Chaná. No tenemos dudas.

¿Cómo eran las sociedades de la ribera? Su perfil es difuso (Cf. Zapata Gollán 1945, Apolinaire y Bastourre 2016). Ulrico Schmidl (1510? - 1599), soldado o sargento de la desgraciada Armada de Pedro de Mendoza que fundara la ciudad de Buenos Aires en 1536, habló de tres naciones a las que consideró muy parecidas en forma de vida y con la misma lengua: Timbúes, Corondas y Quiloazas. Las identificó durante el viaje de Ayolas y Mendoza río arriba y en esa sucesión partiendo de Buenos Aires. El nombre de Corondas parece aludir a la gente que vivía en el hábitat de la que luego fuera San Bartolomé de los Chaná. Los describe como comiendo solamente pescado y carne, sobando cueros de nutria y poseyendo muchas canoas o "barquillas" que podían llevar hasta 16 remeros y fabricadas "con árbol", de 80 pies de largo y 3 de fondo (Cf. D’ Olwer 1963: 574). Iban desnudos aunque las mujeres llevaban un paño de algodón que tapaba "sus partes". Tenían un jefe a quien los conquistadores dieron, a cambio de pescado, cuentas de vidrio, rosarios, espejos, peines y cuchillos. Para seguir hacia el norte, les dieron dos indios carios que tenían cautivos para que los guiaran "y a causa de la lengua". Y nada más.

Un poco menos que una década antes Luis Ramírez de la Armada de Sebastián Gaboto escribió una Relación de Viaje (1528). Su relato enumera los "trabajos" que sufrió la expedición, los malestares y enfermedades, el encuentro con hombres de la expedición de Juan Díaz de Solis (“Diez”) y el ascenso de las naves por el Paraná. Llegando al Carcarañal un río que según los indígenas nacía en la sierra y en donde había metales preciosos y, más allá el mar, que Ramírez identifica con el Mar del Sur. A la fortaleza de Gaboto llegan naciones y lenguas diversas: Caracaris, Chanás, Mbeguás, Chaná Timbus y Timbus. De todos ellos sólo los Carcarais y los Timbú eran agricultores de abatí (maíz), calabazas y habas. Los demás vivían de la caza y del pescado. Los españoles llegaron acompañados de Querandíes, que eran esbeltos, cazadores armados con puntas de flecha y "pelotas de piedra", redondas y grandes como puños con una cuerda atada que las guía ${ }^{3}$.

En el contenido de La Boca había pocos líticos: manos de moler, bola de boleadora, puntas de proyectil (Figuras 9 y 10). Atestiguan no solamente el uso de estos implementos sino también una interacción social con poblaciones distantes como las de las sierras pampeanas o con las gentes de la llanura que tenían acceso a las fuentes de materias primas de las sierras del sur. 

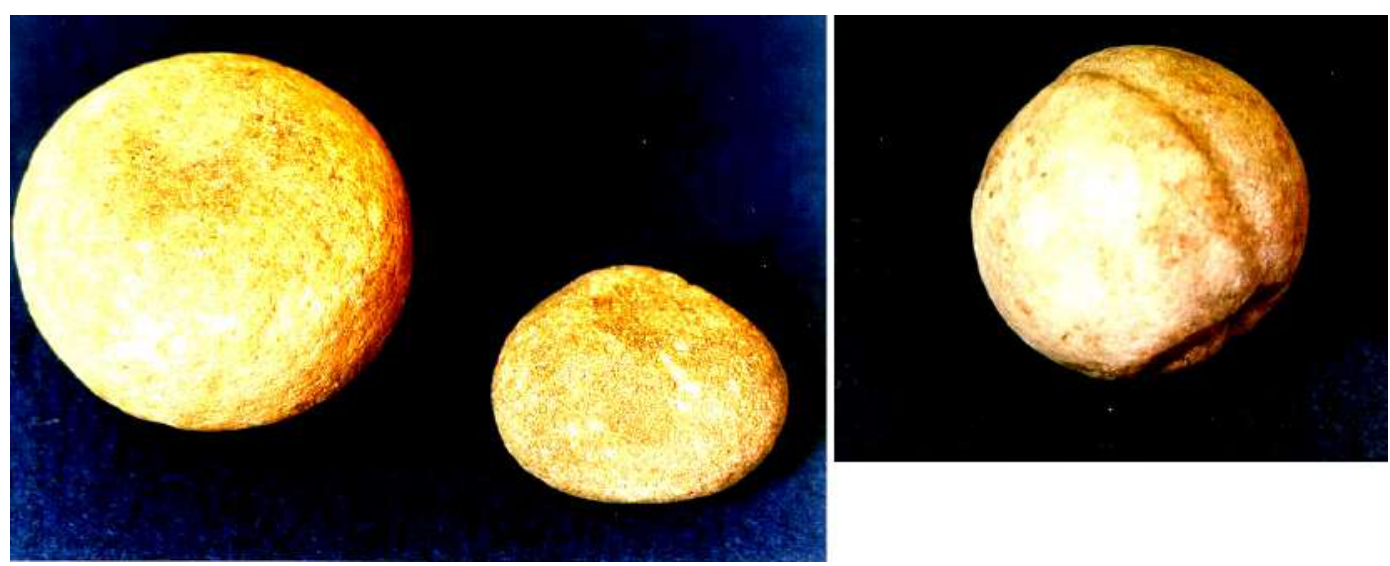

Figura 9. Manos de moler; bola de boleadora. Granitoides feldespáticos.
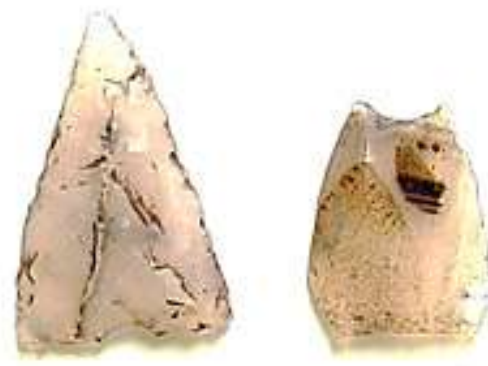

Figura 10. Puntas de Proyectil. Cuarzo cristalino.

\section{Sitio}

Un sitio arqueológico es una unidad física y evolutiva, en un medio o ambiente que posee con factores específicos que promueven su formación y transformación. Todo sitio arqueológico puede exhibir un contenido enterrado, aflorante o aéreo (en el caso de tener estructuras y constructivos) en un específico estadio de definición o resolución informativa. Su emplazamiento informa sobre procesos estándares y variantes. Unos y otros conducen al final de un sitio arqueológico: un final lento o un final catastrófico.

En ese sentido, La Boca de Monje es la realidad invertida de la que fuera San Bartolomé de los Chaná, una reducción chaná aunque allí hubo cohabitación con guaraníes y, al menos, un español de Santa Fe, La Vieja: un sacerdote franciscano que organizó evangelización e iglesia. Era un paraje periférico, sobre costa firme pero orientado a la economía ecológica de las islas del Coronda. Era y es un ambiente de gran energía hídrica. Un paisaje se agua que proveía pesca, caza, leña y chacra.

De acuerdo con las costumbres y legislación civil y religiosa del sistema colonial, la gente era erradicada de su lugar de vida ordinario o habitual para ser llevada con su autoridad tradicional (jefe, cacique, curaca) a un asentamiento "virtuoso" donde habría de vivir de acuerdo con las normas del catolicismo y bajo tutela del encomendero al cual el Rey había cedido la tierra por una vida primero y por dos hasta la extinción de este sistema de propiedad. En el virreinato del Perú, esto ocurrió durante el reinado de Carlos IV quien emitió un edicto sobre su anulación en 1791. 
La evolución del sistema fue la siguiente: sistema de tributación a un señor en la Edad Media Europea + Repartimiento de Indios (Real Provisión del 20 de diciembre de 1503 + Creación de la encomienda en América y Filipinas como derecho otorgado a un español para percibir tributo, evangelizar los indios y "protegerlos" + Leyes de Burgos (1512: regulación del sistema de trabajo) + Provisiones para que solo fueran encomendados los indios que no tuvieran medio de vida (1518) + requisito de que para que hubiera nuevas encomiendas se tendría que tener aprobación religiosa (1527) + Leyes Nuevas que suprimen las encomiendas (1542). Se pueden considerar instaladas informalmente por Colón en La Española (1492), consolidadas desde 1523 y terminadas en decadencia desde fines del siglo XVII (Palomeque 2000).

El vastísimo territorio que controlaba Asunción fue dividido por Real Cédula del 16 de diciembre de 1617 (por gestión de Hernandarias ante Felipe II) en Gobernación del Paraguay (Asunción, Villa Rica del Espíritu Santo y Ciudad Real) y Gobernación del Río de la Plata (Concepción del Bermejo, Corrientes, Santa Fe, Buenos Aires, Río Grande del sur).

San Bartolomé, entonces, se ubica en un tiempo de re-estructuración legal del territorio santafesino; Santa Fe la Vieja (1573) aún no se había trasladado ni abandonado (1660); la región se habría constituido en porción de la Gobernación de Buenos Aires dos años después de su fundación y su encomendero Pero Gómez no logró - después- que su familia se convirtiera en hacendada dadas las deudas que lo obligaron a enajenarla (Calvo 1999).

Parece que el tipo de encomienda de la época fue la de indios originarios, derrotados en guerra o capturados y puestos en servidumbre de por vida (Salinas 2015). En la decadencia de la institución, sin embargo, los vecinos más pudientes podían conservar a "sus" indios (Areces et al, 1993). A diferencia de las monumentales ruinas jesuíticas del Paraguay, San Bartolomé apenas fue un campamento rural.

\section{Realidad invertida}

La Boca, y ocupando media hectárea, está el testimonio de San Bartolomé. No por estructuras ni por una clara funcionalidad de planta sino por un contenido integrado casi exclusivamente por cerámicas arqueológicas (indígenas y españolas) y cuentas de vidrio veneciano. Su nivel de resolución es muy débil por el tenor de la ocupación original del hábitat propio de la adscripción tribal que suponía el sistema de encomienda-reducción (apenas un campamento sostenido por poco tiempo) y en parte por el uso del suelo, especialmente desde mediados del siglo XX cuando a los pocos pobladores pescadores de río se sumaron actividades de pesca deportiva y un balneario con mesas y asadores para el disfrute turístico a los que luego se agregaron, por gestión municipal, algunas instalaciones para confort de la estadía, los baños públicos. Estas actividades inyectaron en la estratigrafía del nivel superior alambres, vidrios, huesos de vaca. Para la defensa del predio respecto a la erosión, el municipio construyó una pared de concreto sobre el Coronda y el Monje para evitar la erosión lateral, especialmente la del Coronda cuya corriente es mucho más voluminosa y veloz que la del Monje. Eso es lo que colapsó en 2019.

¿Por qué "realidad invertida"? Porque la actividad social que formó el sitio resulta aniquilada por la física del sitio. Lo que fueron acciones rutinarias - por ejemplo el trabajo o el rezo- se verifican por fragmentos de materiales en una matriz orgánica enriquecida por la dinámica local de la muerte de flora y fauna. Esa realidad invertida es parcialmente iluminada por la documentación, en este caso, una visita que censó a los moradores y que ya la señaló como en decadencia. El contexto histórico de esa excursión fue el de una rebelión indígena en Concepción del Bermejo que llevó al Gobernador de Buenos Aires, Diego de Góngora a Santa Fe a principios de 1619; su empadronamiento de los indios y una peste que se 
estaba extendiendo (Cf. Molina 2000).

Lo que no se ve, lo que no es tangible en la materialidad de La Boca es el tipo de sociedad colonial que la produjo. Desde el siglo XIV, hubo una creciente importancia del comercio en las ciudades europeas que contribuyó a la desarticulación del feudalismo. En España el proceso fue más lento y trasladó a América las instituciones que se derivaron de ese sistema político-social. Con el tiempo, la tierra -su base- empezó a comercializarse. La diferencia estuvo en que en España no hubo conflicto religioso que en el resto de Europa se desenvolvió como Reforma protestante. Puede considerarse como un año clave el de 1580 porque comienza la venta de tierras y el cercado de los campos en Inglaterra, desencadenando acontecimientos que no iban a tener repercusión sino hasta mucho tiempo más tarde en el Río de la Plata (Cf. Moore 2002).

En el período en que San Bartolomé estuvo activa -comienzo del siglo XVII- los historiadores señalan una intensa recesión que explican por un exceso de oferta (o falta de demanda) y el tránsito hacia transacciones dinerarias con menoscabo de la plata. El derrotero de esta nueva realidad iba a culminar con la formación de un Estado unificado y monopólico, auspicio de un futuro Estado-Nación como contrapartida de la dispersión feudal de la autoridad. El poder político se habría de concentrar en la riqueza mercantilista (Cortés Conde 2003). Esto destruiría finalmente la aristocracia urbana y rural como la de los beneméritos de Santa Fe La Vieja que fue el fundamento de la frustrada San Bartolomé.

\section{Excavaciones}

Las excavaciones arqueológicas son intervenciones que resultan de decisiones tomadas -habitualmente- en terreno y que siempre están dotadas de incertidumbre. En La Boca (o San Bartolomé) se realizaron a lo largo de poco más de 10 años las siguientes operaciones de relevamiento sobre la entidad biofísica del sitio y a partir de su topografía:

- Determinación de áreas de exposición del depósito por erosión, tránsito y obra pública.

- Relevamiento litoestratigráficos del frente de barranca en el arroyo Monje y en el Coronda.

- Relevamiento de playa en bajante con distribución de materiales volcados desde la barranca por erosión.

- Sondeos estratigráficos en el área de sitio entre margen sobre Coronda y Torre de Agua, incluyendo el interior de algunas viviendas.

- Definición de un área crítica sobre la base del criterio de presunción de mayor desarrollo y preservación estratigráfica en el ángulo sureste del balneario.

- Aprovechamiento para el registro estratigráfico de una excavación de obra.

- Excavación de una superficie final de 35 metros cuadrados, avanzando hacia el contacto intercapa entre el humus y el horizonte loéssico carbonatado. Se extrajo el material arqueológico mediante el sistema posicional (tridimensional completo).

El conjunto compacto de matriz y materiales arqueológicos siempre es entrópico, es decir, susceptible de desestabilizarse por causas naturales o humanas. Algunos factores son consistentes y recurrentes. Otros, erráticos y ocasionales. El desbarranque del 2019 entra en esta última categoría pero lo explica la situación estructural del sitio.

Esta porción de la barranca tiene dos tipos de erosión. Una que podríamos llamar de reducción lateral y otra de reducción planar (Figura 12). Ambas han estado siempre activas y su dinámica depende de 
las alternancias de creciente/bajante. Cuando la creciente la columna sedimentaria se impregna de agua y es "comida" tanto en su frente hacia el Coronda como hacia el Monje. Cuando hay bajante quedan en la playa tiestos cerámicos formando una alfombra de corta duración porque se los llevan el tránsito de personas y el paso de ganado que baja todos los días a las islas para pastar. El sitio ha sido reducido - estiman los vecinos- más de treinta metros en el perfil que da hacia la corriente mayor. Para evitarlo, se construyó un muro de contención de cemento pero no ha resultado indemne del embate del agua. La reducción planar produce el efecto de aplanamiento del perfil general; la ocasiona el tránsito de personas, el uso de los asadores y las raíces de los árboles. Esta erosión no solamente quita sedimento sino que también incita el descenso gravitatorio de materiales intrusivos en los primeros centímetros de la estratigrafía.

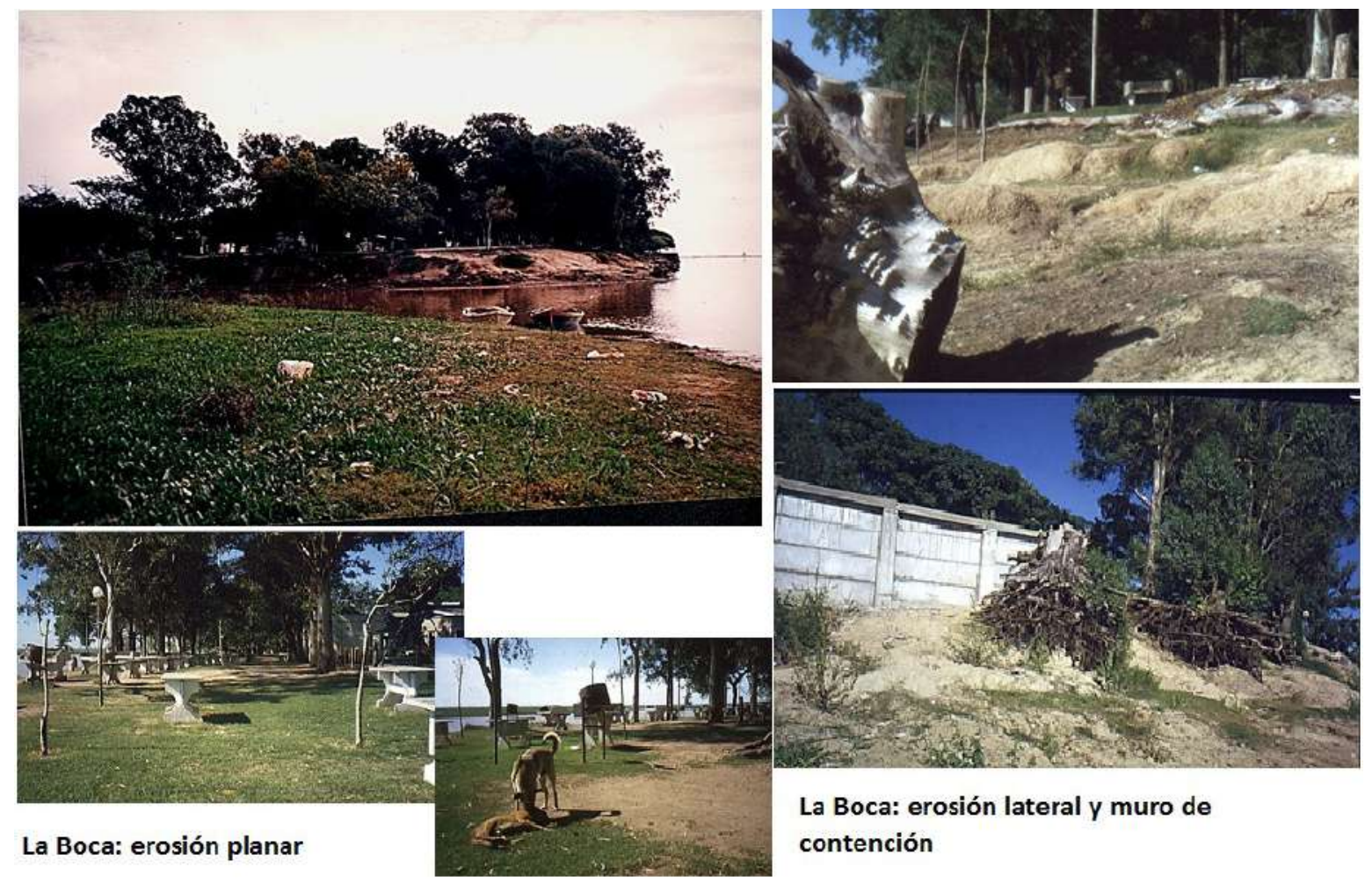

Figura 12. La Boca: tipos de erosión predominante.

\section{Imagen de sitio}

La imagen de sitio es el resultado de las teorías -marcos conceptuales, interpretativos, explicativos- que se le apliquen.

Un sitio colonial siempre tiene sobre sí el peso de la historiografía (a diferencia de los precolombinos, prehistóricos, prehispánicos en América), sus datos y sus interpretaciones. Es difícil dejarla de lado.

Por otra parte, la física concreta en la que repara la arqueología tiene su propio marco teórico, de orden geológico, geomorfológico, químico y biológico. Los enfoques que más han influido en la arqueología contemporánea han sido el de sistema y el de adaptación. Ambos inciden la manera en que se 
organiza la información y son susceptibles a la matematización y al rastreo de tendencias tanto a nivel macro (sociológico,económico) como micro (carácter del registro arqueológico en su escala geográfica).

El sitio es la unidad microgeográfica menor y, por lo tanto, sometida a las variaciones que se diluyen en la escala macro. Los pobladores locales son sensibles a estas variaciones mientras que el período de estudio arqueológico no induce esa sensibilidad. Rara vez modifican la imagen forjada por la teoría de investigación.

Caben algunas afirmaciones relativas a las implicancias de un estudio de sitio en el marco de la Arqueología Histórica (Rocchietti 2002, 2003, 2019).

En primer lugar, las dimensiones espaciales de un sitio como San Bartolomé solamente son un punto de partida porque la confirmación de su identidad colonial depende en gran medida de la documentación de archivo y del diagnóstico cronológico que brindan las mayólicas españolas y las cuentas de vidrio. Por lo tanto, el foco analítico está en una dimensión intangible por fuera del emplazamiento y de la estratigrafía (la documentación asociada no indica dónde estuvo la reducción). La resolución del registro se define en el laboratorio y mucho menos en el campo.

La Arqueología Histórica es un campo que comenzó con debilidad de reconocimiento disciplinar en la Argentina pero luego se afianzó (Gómez Romero y Spota 2006; Rocchietti y De Grandis 2015 b; Landa y Ciarlo 2016; Calvo y Cocco 2016), Por fuera de la discusión relacionada que todo sitio arqueológico es histórico, lo cierto es que la asociación documental exige una conceptualización historiográfica, lo cual implica un trabajo asociativo con los historiadores. Esto significa que esta arqueología es intensa y primordialmente asociativa.

Un sitio colonial en la ribera del Paraná y sus islas requiere una arqueología subacuática por dos motivos: uno es la erosión vertical o lateral que derrumba en el fondo fluvial una parte importante de los restos; el otro es que ese fenómeno reduce selectivamente el repertorio de la cultura material en el registro arqueológico.

La arqueología litoral es compleja e induce a confusiones: en nuestro caso, la prospección en las islas cercanas procurando localizar sitios indígenas o reducciones relacionados con San Bartolomé solamente brindó una nebulosa temporal aunque constató un trasfondo de consistencia de la ocupación islera de los pobladores pre-hispánicos por lo que denominamos a esa coherencia Formación arqueológica (Rocchietti et al 2008; Rocchietti y De Grandis 2013).

La imagen de sitio resulta un conglomerado formado por lo que es visible (los restos) y lo intangible que supone que ella expresa la experiencia social de los tiempos coloniales y republicanos. Esto es tanto empírico como teórico (Ramos y Hernández de Lara 2011; Cf. Areces 2012; Rocchietti y De Grandis 2012). El modelo esperado (Rocchietti y Poujade 2013) por nosotros tenía un perfil de asentamiento misional o de pequeña comunidad cristiana; el registro efectivo, en cambio, ofreció una domesticidad multiétnica.

\section{Retrodicción y proacción}

Las condiciones microvariables del nivel local se insertan en una serie de larga duración que requiere una lectura ambiental retrodictiva; esto es, la estadística de las variables ambientales en un periodo largo como la evolución holocénica de la cuenca o corto como el último siglo o el último ciclo agrario. La aproximación proactiva requiere decidir sobre la conservación.

El muro de contención de crecientes que se construyó hace casi veinte años provocó un socavón que desmoronó la parte de ribera que él cubría. Afectó el sitio. ¿Era predecible? Sí y no. Sí porque la físi- 
ca de un sitio es una estructura o configuración de largo plazo (las estructuras resisten) pero su duración habrá de ser siempre limitada. No, porque los investigadores lo asignan todo a la acción humana y, en este caso, no al capricho del agua.

\section{Final y finales}

Los finales lentos hacen olvidar que los sitios arqueológicos son finitos y postergan el juicio sobre su valor heurístico. Los finales catastróficos son dramáticos, acuciantes sobre la cuestión de qué se pudo haber hecho para prevenirlo o evitarlo. No solamente se actualiza el tema del valor sino también el problema ético-político dl deber actuar para conservar.

Los pobladores han trabajado, han transitado sin pausa y hasta bailaron sobre el suelo arqueológico de San Bartolomé sin verlo. Algunos de ellos tienen algunas clásicas cerámicas Goya Malabrigo atesoradas en sus casas pero nada más. También los turistas y pescadores deportivos han comido sus asados, se han tirado al sol de la costa y se han embarcado en la playa para ir a las aguas llenas de peces y a las islas para cazar. Tampoco lo han visto.

La no visibilidad deviene de una característica que La Boca comparte con todo el litoral: alfombras de cerámicas arqueológicas, generalmente superficiales y pocos relictos de estructuras (fogones por ejemplo) y ningún constructivo. Es complicado proyectar la imagen del sitio cuando nada parece aflorar de él.

Son las lozas y las cuentas de vidrio las que certifican que ese depósito fue San Bartolomé y son las cerámicas Goya Malabrigo o Chaná y las cerámicas guaraníes las que atestiguan que la reducción fue bi-étnica aunque no podríamos decir si la presencia guaraní fue sistemática o casual. El componente "Guaraní" es bien reconocible en parte por su tendencia al conservadurismo estilítico (Cf. Loponte y Acosta 2013).

No es posible afirmar que los indígenas tuvieran una economía nutriera o pescadora porque sus esqueletos no aparecieron ahí. Tampoco sería adecuado sostener que allí hubo vaquería por la mezcla que provocó el balneario.

¿Integró un sistema San Bartolomé? Históricamente, sí; porque el asentamiento se produjo por razones geopolíticas, económicas y organizacionales de los españoles y criollos de Asunción o de Santa Fe La vieja, coherente con el sistema colonial implantado después de haber anexado a los guaraníes y a las tribus del chaco santafesino.

¿Integró e integra un sistema La Boca? Si. Forma parte de un sistema de sitios coloniales, pre-coloniales y post-coloniales que derivan de un género de vida "islero" que se sostuvo en el tiempo con características bastante homogéneas. Esto dificulta distinguir los registros que se corresponden a uno $u$ otro período si no aparecen materiales europeos ya que el aislamiento y la pobreza hizo de sus contextos una versión despojada de sus respectivas sociedades macropolíticas (Virreinato, República). El sistema, por lo tanto, en un primer nivel, es una colección de registros en el ambiente de río.

\section{Conclusiones}

En un sitio arqueológico convergen relaciones históricas y sociales así como relaciones adaptativas (adecuaciones +estasis) y de desarrollo (su medida es la combinación de tecnología y hábitat) que es la causa de la diversificación de la cultura. Los aspectos adaptativos de una sociedad se pueden agrupar en ecología, estructura social e ideología. San Bartolomé los desplegó de manera desigual porque la expe- 
riencia colonial fracasó y los indígenas volvieron a su género de vida islero: conocimiento, recursos y trabajo. Esto es, a desplegar su capacidad tecnológica.

Las excavaciones arqueológicas no agotaron el sitio pero puede declararse su final. Final de su rendimiento arqueológico por pérdida de densidad de la acumulación de cultura material y trivialidad de los hallazgos. Final físico del emplazamiento residual por colapso del terreno.

¿Fracaso de la predictibilidad?: parcialmente. El sistema hidrológico de la cuenca tiene ciclos; todavía no se advierten efectos intensos del cambio climático global y puede decirse que es predecible. En la región se suele advertir sobre los peligros de las crecientes. El final catastrófico lo produjo la bajante.

\section{Notas}

${ }^{1}$ En: https://www.ellitoral.com/index.php/id_um/206886- IRE.com.ar http://www.informacionregional.com.ar/noticias/monje-764/monje-evalua-eldesmoronamiento-en-la-boca-se-socavo-todo--21493

${ }^{2}$ El ENSO (El Niño/Oscilación del Sur) designa un ciclo de sucesión Niño (calentamiento de las aguas del Pacífico sur que suele ocurrir cerca de la Navidad y que suele repetirse cada tres o siete años) y Niña (contrapartida de aguas frías). La alternancia no es mecánica pero es de alta influencia en el clima del Cono Sur.

${ }^{3}$ En: https://pueblosoriginarios.com/textos/ramirez/carta.html

\section{Referencias bibliográficas}

APOLINAIRE, E. Y L. BASTOURRE (2016). Los documentos históricos de los primeros momentos de la conquista del Río de la Plata (s. XVI - XVII): una síntesis etnohistórica comparativa. Relaciones de la Sociedad Argentina de Antropología XLI (2), junio - diciembre: 1 - 33.

ARECES, N. (2010). Santa Fe La Vieja a través de los registros arqueológicos e históricos. En S. E. Cornero (Compiladora), Pobladores de la antigua Santa Fe de los Quiloazas (Siglos XVI-XVII, Cayastá). Rosario: Consejo Federal de Inversiones, Editorial Ciudad Gótica: 21 - 46.

ARECES, N. (2012). La Arqueología Histórica y los estudios regionales. Revista Teoría y Práctica de la Arqueología Histórica Latinoamericana. Rosario: Centro de Estudios en Arqueología Histórica, Facultad de Humanidades y Artes, Universidad Nacional de Rosario, Año I, número 1, invierno: $11-24$.

ARECES, N., S. LÓPEZ, B. NÚÑEZ REGUEIRO, E. REGIS, E Y G. TARRAGÓ (1993). Santa Fe la Vieja. Frontera abierta y de guerra. Los frentes Charrúa y Chaqueño. Memoria Americana, 2: 7- 40.

AZEÑOLAZA, P., L. ZAMBONI, W. SCIONE Y P. KALESNIK (2009). Caracterización de la región superior del Complejo Litoral del Río Paraná: grandes unidades del ambiente. INSUGEO. Miscelánea 17 (2): 293 - 308.

BONFILS, C.G. (1962). Los suelos del Delta del río Paraná. Factores generadores, clasificación y uso. Buenos Aires: Revista de Investigaciones Agrícolas. T. XVI (3): 257-370.

CALVO, L M. (1999). Pobladores españoles de Santa Fe la Vieja (1573- 1660). Buenos Aires: Academia Nacional de la Historia. 
CALVO, L. M. Y G. COCCO (2016). Introducción. En L. M. Calvo y G. Cocco, Primeros asentamientos españoles y portugueses en la América Central y Meridional. Siglo XVI y XVII. Santa Fe: Editorial Universidad Nacional del Litoral.

CORTÉS CONDE, R. (2003). Historia económica mundial. Desde el medioevo hasta los tiempos contemporáneos. Madrid: Ariel.

CORNERO S. (2018). En las Puertas del Mito: Loros y Peces en el Arte Cerámico de la Costa del Rio Paraná. En: Goya-Malabrigo Arqueología de una Sociedad Indígena del Noreste Argentino. G. Politis y M. Bonomo eds., Editorial Universitaria de la UNCPBA: 89-106.

CORNERO S. (2019). Los Cóndores Andinos del Paraná. Análisis de Cerámicas Catártidas en la Costa del Bajo Paraná. UNRC. Rev. Sociedades de Paisajes Áridos y Semi-Áridos. XII-9.

D’ OLWER, L. N. (1963). Cronistas de las culturas precolombinas. México: Fondo de Cultura Económica.

DE GRANDIS, N. (1998). El rol de las reducciones franciscanas en territorio santafesino a principios del siglo XVII. Primeras Jornadas de Arqueología Histórica de la Provincia y Ciudad de Buenos Aires.

DE GRANDIS, N. (1999).Las cuentas vítreas de San Bartolomé de los Chaná.Sociedad de Arqueología Brasilera. Recife.

DE GRANDIS, N. (2005) Indians and Franciscans at the Beginning of the Seventeenth Century in the reducción of San Bartolomé de los Chaná, Monje, Santa Fe, Argentina. Francis in the Americas: Essays on the Franciscan Family in North and South America. Berkeley, California Academy of American Franciscan History: 553 a 563.

DE GRANDIS, N. (2006). Título: Distribución y jerarquización de los espacios en las primeras reducciones franciscanas del Río de la Plata. $1^{\circ}$ Congreso Nacional de Arqueología Histórica. Buenos Aires: Corregidor.

DE GRANDIS, N. (2006). Cuentas de vidrio e indios reducidos en San Bartolomé de los Chaná. (Monje, Provincia de Santa Fe). Estudios de Arqueología Histórica. Investigaciones argentinas pluridisciplinarias. $2^{\circ}$ Congreso Nacional de Arqueología Histórica. Tierra del Fuego: Museo de la Ciudad de Río Grande. Tierra del Fuego:89 a 97.

DE GRANDIS, N. (2008).Detrás de la cruz. Huellas franciscanas y pueblos originarios en Santa Fe la Vieja. En S.Cornero (Compiladora), Aquellos, los que se quedaron. Arqueología, conservación y museografía. Institución: Rosario: Consejo Federal de Inversiones.

DE GRANDIS, N. (2010). Entre la tierra y el cielo. Las cuentas sagradas en el templo de San Francisco, Santa Fe La Vieja. En S. Cornero (Compiladora), Pobladores de la antigua Santa Fe del Quiloaza. Rosario: Consejo Nacional de Inversiones y Editorial Ciudad Gótica: 67 - 83.

DE GRANDIS, N. (2012). Barcos mercantes y tráfico comercial en la costa del Río de la Plata. Las botijas de media arroba. Rosario: Centro de Estudios en Arqueología Histórica, Facultad de Humanidades y Artes, Universidad Nacional de Rosario. Revista de Teoría y Práctica de la Arqueología Histórica Latinoamericana. Año I, número 1, invierno: 109 - 118. 
GÓMEZ ROMERO, F. Y J. C. SPOTA (2006) Algunos comentarios críticos acerca de 15 años de Arqueología en los Fortines Pampeanos. Relaciones de la Sociedad Argentina de Antropología, XXXI: $161-185$.

IRIONDO, M. Y E. SCOTTA (1978). The evolution of the Paraná River Delta. Proceedings of the International Symposium on Coastal Evolution in the Quaternary. San Pablo: INQUA: 405 - 418.

IRIONDO, M. (1993). El Litoral. En: M. Iriondo (Editor) El Holoceno en la Argentina. Buenos Aires: CADINQUA (INQUA-AGA-CONICET). Volumen 2: 1 - 21.

LANDA, C. G. Y N. C. CIARLO (2016). Arqueología Histórica: especificaciones del campo y problemáticas de estudio en Argentina. Buenos Aires: Filo - UBA. Revista QueHacer, 3: 96 - 110.

LOPONTE, D. Y A. ACOSTA (2013). La construcción de la unidad arqueológica guaraní en el extremo meridional de su distribución geográfica. Buenos Aires: Cuadernos del Instituto Nacional de Antropología y Pensamiento Latinoamericano. Series especiales, número 1(1): 193 - 235.

MALVAREZ, A. 1. (1993). El Delta del rio Paraná como región ecológica. En: Iriondo, M. (Editor), El Holoceno en la Argentina. Paraná: CADINQUA (INQUA-AGA-CONICET), Volumen 2: 81 - 93.

MOLINA, R. A. (2000), Diccionario Biográfico de Buenos Aires, 1580-1720, Buenos Aires, Academia Nacional de la Historia.

PALOMEQUE, S. (2000). El mundo indígena. Siglos XVI - XVIII. En E. Tandeter (Director) Nueva Historia Argentina. La sociedad colonial. Tomo II. Buenos Aires: Editorial Sudamericana: 87 143.

RAMOS, M. Y O. HERNÁNDEZ DE LARA (2011). Hacia una Arqueología Histórica Latinoamericana. En M. Ramos y O. Hernández de Lara, Arqueología Histórica en América Latina. Programa de Arqueología Histórica y Estudios Pluridisciplinarios. Luján: Departamento de Ciencias Sociales, Universidad Nacional de Luján: $1-2$.

ROCCHIETTI, A. M. (1995). La Boca del Monje: un sitio reduccional para indios isleros (siglo XVII). En VIII Reunión Científica de Arqueología Brasileira. Centro de Cultura y Ciencias de la Pontificia Universidad Católica de Río Grande de Porto Alegre. r. Grande do Sul. Brasil: Actas. CD.

ROCCHIETTI, A. M. (2002).Formaciones arqueológicas con documentos histórica asociada: la investigación social del registro arqueológico. En Arqueología Histórica Argentina.Actas del $1^{\circ}$ Congreso Nacional de Arqueología Histórica. Buenos Aires: Ediciones Corregidor: 659 - 668.

ROCCHIETTI, A. M. (2003). Arqueología Histórica: problemas, registros y fronteras. Revista de la Escuela de Antropología, volumen VIII, noviembre: $171-180$.

ROCCHIETTI, A. M. (2005). Arqueología de islas y costas del Paraná santafesino: área Monje-Gaboto. Rosario. Revista de la Escuela de Antropología, X, noviembre: 41 -54.

ROCCHIETTI, A. M. (2007). Economía islera en el Holoceno Tardío: un modelo exploratorio para las distribuciones arqueológicas de la latitud Monje - Gaboto. Paraná: Museo Antonio Serrano. CD.

ROCCHIETTI, A. M. (2019). Arqueología Histórica: programa y dimensiones epistemológicas. Revista 
Teoría y Práctica de la Arqueología Latinoamericana. Rosario: Centro de Estudios en Arqueología Histórica, Año 8, Volumen 8: 9 - 12.

ROCCHIETTI, A. M., N. DE GRANDIS, B. VICIOSO Y M. VALENTÍNI (2008). La Dulce: problemática de transformación de sitio islero. Segundas Jornadas Rosarinas de Arqueología. Departamento de Arqueología. Rosario: Escuela de Antropología. Facultad de Humanidades y Artes. Universidad Nacional de Rosario: 52 - 74.

ROCCHIETTI, A. M. Y N. DE GRANDIS (2011). Problemas de arqueología colonial. San Bartolomé de los Chaná. Reducción y encomienda de Pero Gómez, vecino de Santa Fe la Vieja en el río Coronda. Anuario de Arqueología, año 3, número 3: 293 - 324.

ROCCHIETTI, A. M. Y N. DE GRANDIS (2012). Arqueología Colonial: registros y metodologías. Rosario: Centro de Estudios en Arqueología Histórica, Facultad de Humanidades y Artes, Universidad Nacional de Rosario. Revista de Teoría y Práctica de la Arqueología Histórica Latinoamericana. Año I, número 1, invierno: 89 - 98.

ROCCHIETTI, A. M. Y. N. DE GRANDIS (2016) La reducción franciscana de San Bartolomé de los Chaná: un asentamiento costero del Paraná Argentino. En L. M. Calvo y G. Cocco, Primeros asentamientos españoles y portugueses en la América Central y Meridional. Siglo XVI y XVII. Santa Fe: Editorial Universidad Nacional del Litoral 221 - 237.

ROCCHIETTI, A. M. Y N. DE GRANDIS (2014).San Bartolomé de los Chaná. Economía y Sociedad. VII Congreso Argentino de la Región Pampeana. Secretaría de Cultura e Innovación Tecnológica. Provincia de Santa Fe. (CARPA). Rosario, 5, 6 y 7 de noviembre del 2014. En prensa.

ROCCHIETTI Y N. DE GRANDIS (2015A). Socio-arqueología de San Bartolomé de los Chaná, reducción de indios. Revista de Teoría y Práctica de la Arqueología Histórica Latinoamericana, Año IV, Volumen 4: $88-105$.

ROCCHIETTI, A. M. Y N. DE GRANDIS (2015b). Economía y sociedad en una reducción indígena en el litoral del Paraná. Revista Arqueología Histórica Argentina y latinoamericana, número 10 (1): $91-117$.

ROCCHIETTI, A. M. Y N. DE GRANDIS (2018). La Arqueología Histórica en las islas: problemas de registro y de interpretación. III Congreso Internacional de Arqueología de la Cuenca del Plata. Sao Leopoldo. Sao Leopoldo, Brasil:Unisinos. En prensa.

ROCCHIETTI, A. M. Y R. POUJADE (2013). Problemas metodológicos en la arqueología del Coty Guazú de la Misión de Santa Ana (Misiones, Argentina): una aproximación al registro esperado. Rosario: Centro de Estudios en Arqueología Histórica, Facultad de Humanidades y Artes, Universidad Nacional de Rosario. Revista de Teoría y Práctica de la Arqueología Histórica Latinoamericana. Año I, número 2, invierno: $101-128$.

ROCCHIETTI, A. M., N. DE GRANDIS Y M. S. CARBALLO (1994). Arqueología del área Gaboto - Monje. En Actas y Memorias del XI Congreso Nacional de Arqueología argentina. San Rafael. Mendoza: Revista del Museo de Historia Natural de San Rafael, tomo XIV, No 14, 1994: 264-266.

ROCCHIETTI, A. M., N. DE GRANDIS, B. VICIOSO Y L. MARTÍNEZ (1996). La Boca del Arro- 
yo Monje. Los indios isleros y la invasión europea en el siglo XVI. En Primeras Jornadas de la Cuenca del Plata y Segundas de Etnolinguística. Escuela de Antropología. Rosario: Facultad de Humanidades y Artes. Universidad Nacional. de Rosario. Tomo IV, Arqueología.

ROCCHIETTI, A. M., N. DE GRANDIS Y M. VALENTINI (2005) Arqueología de costas e islas del Paraná santafesino: Área Monje-Gaboto. Rosario: Revista de la Escuela de Antropología 11: 41-51.

ROCCHIETTI ANA MARÍA, NÉLIDA DE GRANDIS Y MÓNICA VALENTINI (2007). Arqueología y paisaje cultural - natural de los indios isleros de la Provincia de Santa Fe. En M. Valentini (Compiladora). Rosario: Departamento de Arqueología. Escuela de Antropología. Universidad Nacional de Rosario e ICOMOS. CD.

SALINAS, M. L. (2015). Población Indígena "urbana" y encomenderos en Santa Fe La Vieja según la visita del oidor Andrés Garabito de León. 1650. Diálogos, Volumen 19, número 2, marzo - agosto: $433-463$.

VALENTINI, M. (2003). "Reflexiones bajo el agua". En UNESCO. Patrimonio cultural subacuatico América Latina y el Caribe, Underwater cultural heritage. Publicación para promover la convención de la UNESCO sobre la protección del patrimonio cultural subacuático. La Habana: Oficina Regional de Cultura para América Latina y el Caribe de la UNESCO: 36-45 versión en español y 104-111 versión en inglés.

VALENTINI, M. (2006). Tierra y Agua, una continuidad en el proceso de investigación. En C. del Cairo y C. García, Más que tesoros, historia sumergidas. Hacia la protección del patrimonio cultural subacuático en Latinoamérica Bogotá, Colombia: Editorial Universidad Externado de Colombia: 229 a 246.

VALENTINI, M Y J. GARCÍA CANO (2001). La integración subacuática en sitios de la región nordeste. Los casos de Santa Fe La Vieja y La Boca del Monje, Provincia de Santa Fe, Argentina. En Memorias del Congreso Científico de Arqueología Subacuática de ICOMOS. Colección Científica. México: CONACULTA. Instituto Nacional de Antropología e Historia: 113-119.

VALENTINI, M. Y J. GARCÍA CANO (2003). El registro arqueológico subacuático como un componente necesario para obtener un análisis integral de sitios en regiones con importante presencia de cuencas acuíferas. En M. Ramos y E. Néspolo (Editores) Signos en el tiempo y rastros en la tierra. III Jornadas de Arqueología e Historia de las regiones Pampeana y Patagónica. Luján: Universidad Nacional de Luján, Departamento de Ciencias Sociales. 271-276.

ZAPATA GOLlÁN, A. (1945). Los Chaná en el territorio de la Provincia de Santa Fe. Santa Fe: Publicaciones del Departamento de Estudios Etnográficos y Coloniales.

Recibido: 10-04-2020

Aceptado: 23-06-2020 